\title{
A MODERNIZAÇÃO DA AGRICULTURA E OS IMPACTOS NA ORGANIZAÇÃO SOCIOESPACIAL DO MUNICÍPIO DE TOROPI-RS
}

\author{
Andriele Prunzel Koglin ${ }^{1}$ \\ Meri Lourdes Bezzi ${ }^{2}$
}

\section{Resumo}

A modernização da agricultura resultou em considerável impacto para a organização socioespacial do Brasil e, especificamente, do Rio Grande do Sul. Deste modo, este trabalho aborda as transformações oriundas do incremento produtivo de algumas atividades agrícolas, somado à utilização de agrotóxicos, à inserção de maquinários e à expansão do êxodo rural, o que evidencia as alterações produtivas ocasionadas no município de Toropi-RS. Para responder a tal questão, foram realizados levantamentos de dados estatísticos secundários no site do IBGE, além da realização de entrevistas com agricultores familiares, representante da EMATER, da Granja Toropi e da COOMAT. Nesta unidade territorial, aproximadamente $60 \%$ das propriedades rurais possuem, na produção fumageira, a sua principal atividade econômica. $\mathrm{O}$ setor primário obteve incremento no cenário local devido à dificuldade dos produtores familiares em se modernizarem e permanecerem produzindo soja. Além disso, a presença de agroindustriais, no município, tem promovido a reorganização espacial e, por conseguinte, marcado o "novo rural" no panorama local.

Palavras-chave: Organização espacial, agricultura familiar, modernização da agricultura, Toropi-RS.

\section{THE MODERNIZATION OF AGRICULTURE AND ITS IMPACT ON THE SOCIO-SPATIAL ORGANIZATION IN TOROPI-RS}

\begin{abstract}
The modernization of agriculture has resulted in considerable impact on the socio-spatial organization in Brazil and specifically in Rio Grande do Sul. This paper addresses the transformations resulting from the productive increase of some agricultural activities, in addition to the use of agrochemicals, the insertion of machinery and the expansion of the rural exodus, which show productive changes caused in the municipality of Toropi-RS. To answer this question, secondary statistical data were collected on IBGE website and interviews were conducted with family farmers, representatives of EMATER, Granja Toropi and COOMAT. In this territorial unit, approximately $60 \%$ of rural properties have, tobacco production, as their main economic activity. The primary sector has increased in the local scenario due to the difficulties faced by family producers to modernize and to remain producing soy. In addition,

1 Graduanda em Geografia (licenciatura) pela Universidade Federal de Santa Maria (UFSM). Email: andrielekog@gmail.com.

${ }^{2}$ Doutora em Geografia pela Universidade Estadual Paulista Júlio de Mesquita Filho/Rio Claro (1997). Docente Titular no Departamento de Geociências/UFSM, atuando nos Cursos de Graduação em Geografia Bacharelado e Geografia Licenciatura Plena e no Programa de Pós-graduação em Geografia da UFSM. Email: meribezzi@yahoo.com.br.
\end{abstract}


the presence of agroindustrials has promoted an spatial reorganization in the municipality and, consequently, has marked the "new rural" in the local panorama.

Keywords: Spatial organization, family agriculture, modernization of agriculture, Toropi-RS.

\section{LA MODERNIZACIÓN DE LA AGRICULTURA Y LOS IMPACTOS EN LA ORGANIZACIÓN SOCIALESPACIAL DEL MUNICIPIO DE TOROPI-RS}

\section{Resumen}

La modernización de la agricultura resultó en grandes impactos para la organización socioespacial de Brasil y, específicamente, de Rio Grande do Sul. De este modo, este trabajo aborda las transformaciones oriundas del incremento productivo de algunas actividades agrícolas, sumado a la utilización de agrotóxicos, inserción de maquinarias y la expansión del éxodo rural, evidenciando las alteraciones productivas ocasionadas en el municipio de ToropiRS. Para responder a esta pregunta, se recopilaran datos estadísticos secundarios en el sitio web del IBGE y se realizaron entrevistas con agricultores familiares, representantes de EMATER, Granja Toropi y COOMAT. En esta unidad territorial, aproximadamente el $60 \%$ de las propiedades rurales poseen, en la producción fuumbrera, su principal actividad económica. El sector primario obtuvo incremento en el escenario local debido a la dificultad de los productores familiares en modernizarse y permanecer produciendo soja. Además, la presencia de agroindustriales ha promovido la reorganización espacial en el municipio y, por consiguiente, marcado el "nuevo rural" en el panorama local.

Palabras-clave: Organización espacial, agricultura familiar, modernización de la agricultura, Toropi-RS.

\section{INTRODUÇÃO}

O espaço geográfico é transformado com o trabalho e se (re)organiza a partir da introdução de novas técnicas, de acordo com os interesses do capital. Portanto, o espaço não é estático. Ele é modificado constantemente, conforme o período histórico (SANTOS, 1992). Neste sentido, no espaço rural brasileiro, o processo de modernização da agricultura trouxe profundas transformações ao campo e ao modo de vida de seus habitantes.

A partir desta premissa, o recorte territorial selecionado para estudo foi o município de Toropi-RS (Figura 1), uma vez que este é essencialmente rural, tanto em aspectos populacionais quanto econômicos, com predomínio de pequenas propriedades de base familiar. O município, está localizado na região central do Rio Grande do Sul, na zona de transição do Rebordo do Planalto, entre a Depressão Central e o Planalto Meridional do estado gaúcho. 


\section{Figura 1: Localização do Município de Toropi-RS}

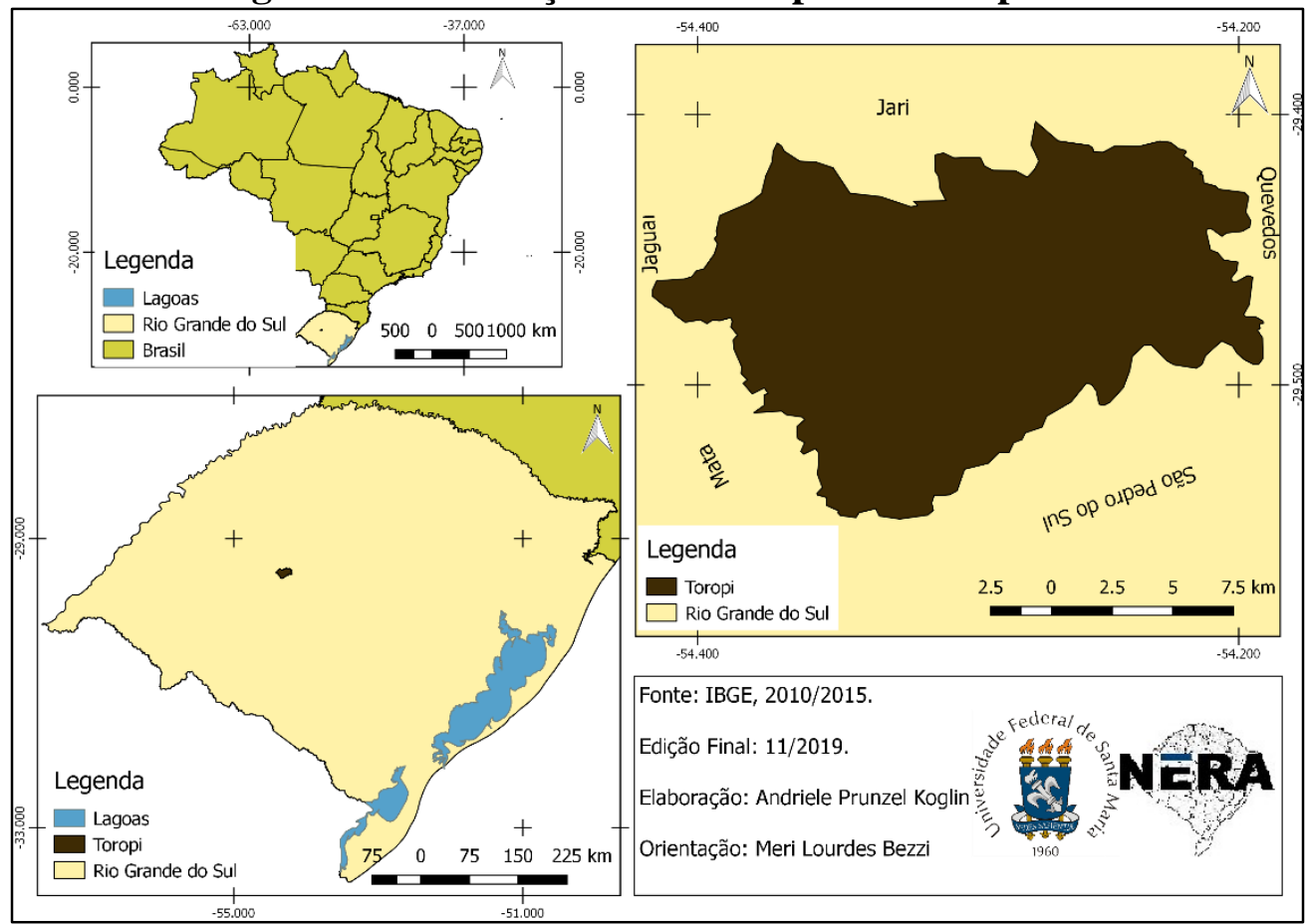

Fonte: IBGE, 2010/2015. Elaborado pelas autoras (2019).

Neste sentido, o objetivo deste trabalho é discutir quais foram as principais transformações resultantes da modernização da agricultura, evidenciando as alterações deste processo no município de Toropi-RS. Salienta-se que a escala temporal de análise se refere ao período de 1997 a 2018, em virtude da emancipação desta unidade territorial no ano de 1997, a qual, até então, era pertencente ao município de São Pedro do Sul-RS.

Para responder a tal questão, foram realizados levantamentos de dados estatísticos secundários no site do Instituto Brasileiro de Geografia e Estatística (IBGE). Posteriormente, houve a produção de informação por meio da técnica da entrevista com questionário semiestruturado. Para enriquecer e corroborar com as análises foram capturadas fotografias para exemplificar a realidade verificada in loco.

Segundo o IBGE (2006) o município possui um total de 931 estabelecimentos rurais. Destes, foram efetuadas 43 entrevistas, perfazendo uma amostragem de 4,6\% da população total. Salienta-se que o município possui 2 distritos, os quais, totalizam 22 localidades. Desta forma, as entrevistas foram distribuídas proporcionalmente entre cada localidade aleatoriamente, ou seja, duas entrevistas por localidade, além de uma entrevista em uma outra localidade que possui apenas um estabelecimento rural. 
$\mathrm{Na}$ produção de informação no trabalho de campo, foram realizadas entrevistas direcionadas, em um primeiro momento, aos moradores da área rural, sobretudo com agricultores, onde optou-se por produzir informações de uma parcela representativa da população, visando entender os aspectos relacionados à propriedade, à produção, à utilização de mão de obra e às "tecnologias" na produção.

Posteriormente, a produção de informação foi direcionada a dois setores dinamizadores da economia local: a Cooperativa Mista dos Agricultores de Toropi (COOMAT) e a Granja Toropi. Estas forneceram subsídios para se compreender o seu papel na reorganização do espaço. No terceiro momento, foi realizada a produção de informação com um técnico extencionista da Empresa Brasileira de Assistência Técnica e Extensão Rural (EMATER) do município, tendo por objetivo visualizar as atividades predominantes, bem como, os incentivos e políticas públicas em nível local para a diversificação da produção nas propriedades.

\section{A REORGANIZAÇÃO CAPITALISTA DO ESPAÇO}

A geografia, segundo Moreira (2014, p.7), "é o estudo de como o arranjo do espaço reflete e ao mesmo tempo organiza as relações de troca metabólica que o homem e a natureza estabelecem entre si no curso da história”. Assim, entende-se que a geografia tem por objeto de estudo a organização espacial, à qual é um reflexo das relações homem - natureza de acordo com as necessidades de cada sociedade num dado momento histórico.

Neste sentido, Corrêa (2003, p.54) nos diz que é "pelo trabalho social que os homens estabelecem relações entre si e, a partir destas, com a natureza”. Deste modo, é por meio do trabalho acumulado ao longo do tempo que o ser humano transforma a primeira natureza em segunda natureza, ou seja, a natureza primitiva em natureza construída.

Salienta-se que nas sociedades capitalistas, para Corrêa (2003, p.60-61),

[...] este trabalho realiza-se sob o comando do capital, quer dizer, dos diferentes proprietários de diversos tipos de capital. Também é realizado através da ação do Estado capitalista. Isto quer dizer que o capital e seu Estado são os agentes da organização do espaço. Daí fala-se em espaço do capital. A ação do capital não se verifica de modo uniforme, quer em termos temporais ou espaciais. Há uma diferenciação espaço-temporal nos investimentos do capital.

Pode-se afirmar, então, que o espaço produzido e reproduzido nas sociedades capitalistas é resultado dos interesses do capital em cada lugar e tempo. Somado a isto, Santos (1992, p.12) enfatiza que "cada lugar é uma combinação de técnicas qualitativamente 
diferentes, individualmente dotadas de um tempo específico - daí as diferenças entre os lugares". Portanto, cada lugar é uma combinação de técnicas heterogêneas agregadas aos distintos valores aplicados, o que resulta na diferenciação dos lugares, refletindo, por consequência, nas distintas dinâmicas espaciais.

É importante relembrar que o capital é uma destruição criadora, ou seja, através de suas crises de superprodução ele se fortalece e cria novas funções, renovando suas condições de acumulação. Para sua expansão é necessário um conjunto de fatores, sendo que um deles é a demanda efetiva expandida por produtos, o qual é elaborado pela (1) penetração do capital em formas preexistes afim de reorganizar essa atividade e a tornar ainda mais lucrativa (por exemplo, a transformação da agricultura de subsistência em agricultura empresarial); (2) criar novos desejos e necessidades à população; (3) estimular o crescimento populacional, com o intuito de ter um exército de reserva e, por consequência, mão de obra barata; (4) e, por fim, se propagar geograficamente para novas regiões, expandindo-se rumo ao "mercado mundial" (HARVEY, 2006).

Salienta-se que os fatores responsáveis pela expansão do capital estão intimamente relacionados a organização do espaço. Deste modo, o espaço é um produto do trabalho e este, por sua vez, realiza-se sob o comando do capital, se reorganizando. Nesta perspectiva, Andrade (2002, p.35) afirma que devemos “[...] refletir levando em conta que o espaço nunca está organizado de forma definitiva, que ele não é estático, ao contrário, é profundamente dinâmico e vai se modificando dialeticamente de forma permanente".

Ainda em relação a dinâmica do espaço, Santos (1988, p.95) afirma que “[...] o que hoje aparece como resultado é também um processo, que amanhã vai tornar-se uma outra situação. Toda situação é, do ponto de vista estático, um resultado, e do ponto de vista dinâmico, um processo". Portanto, quando fazemos um determinado recorte histórico e espacial precisamos levar em consideração que isto não é suficiente, por si só, para compreender o fenômeno pois este está em constante transformação e é apenas uma parte da totalidade do espaço e do processo.

Além disso, evidencia-se que a organização espacial não é apenas um reflexo da sociedade, mas também uma condição para as futuras gerações. Portanto, conforme Corrêa (2003, p.55), é necessário que no processo de produção do espaço sua continuidade seja pensada, bem como sua própria reprodução. Sendo que 
[...] é necessário que se criem no próprio processo de produção as condições de sua reprodução; sendo assim, o processo de produção é também de reprodução. Um grupo social tem a mesma necessidade; caso contrário, teríamos o absurdo do mesmo durar apenas o período de uma geração.

Nesta perspectiva, segundo Santos (1992, p. 13), a organização espacial também é uma condicionante para a manutenção das classes sociais visto que o espaço é pensado para "[...] prolongar a vigência de uma dada função, de maneira a lhe atribuir uma continuidade e regularidade que sejam favoráveis aos detentores do controle da organização".

Destaca-se que as formas espaciais estão carregadas de um valor econômico e simbólico. Sendo assim, através da penetração do capital em antigas formas, estas são adaptadas aos interesses do presente, apresentando-se à uma nova funcionalidade. Então, a reconfiguração da agricultura, por meio do processo de incremento e modernização do setor, possui um papel significativo na dinâmica da organização do espaço. Corrêa (2003, p. 63-64) chama atenção quando afirma que

\footnotetext{
Ao introduzirem um novo produto agrícola e a modernização tecnológica em uma área rural, as grandes corporações podem, direta ou indiretamente, alterar sua estrutura agrária: concentração fundiária, mudanças nas relações de produção com uma nova força de trabalho constituída por boias-frias, emigração do excedente demográfico, etc. Aceleram, ainda, o processo de exaustão dos solos e, em relação às cidades da área, alteram as suas funções, pela diminuição da população de sua área de influência e pelo novo modelo de demanda rural.
}

Neste contexto, após o incentivo à industrialização na Era Vargas a necessidade de um exército de reserva nos centros urbanos aumentou e o estímulo à modernização da agricultura, o espaço rural passou a incorporar novas características além de modificar suas relações com a cidade. Assim, essas transformações são visualizadas na concentração fundiária, na inserção de novas atividades no campo, no êxodo rural, entre outras, o que acaba por modificar tanto a paisagem rural quanto as próprias relações do/no campo, resultando no chamado "novo rural".

\section{A MODERNIZAÇÃo CONSERVADORA DA AGRICULTURA}

No contexto pós-guerra (1939-1945) a geopolítica mundial passou por profundas transformações. As ações viabilizadas pelos países centrais e, em especial, pelos Estados Unidos, buscaram uma nova estratégia para acumular capital e se manter como as principais potências econômicas do mundo. Para isto, os ditos países "subdesenvolvidos" ou de Terceiro Mundo foram vistos como um território a servir aos interesses do capital, sendo que ao mesmo 
tempo, suas ações eram concretizadas sob o pretexto de que ele estaria auxiliando esses países no combate a "ameaça comunista". (BRAGA, 2002)

Ainda conforme Braga (2002) dentre os artifícios de ampliação e acumulação capitalista norte americana, destaca-se a implantação do ideal de expansão agrícola, a qual foi preconizada pela Revolução Verde. Esta estratégia de ampliação do setor agropecuário passa a fazer parte do contexto de diversas nações mundiais a partir da década de 1950, devido os ideais de inserção do pacote tecnológico.

Em relação ao panorama produtivo agropecuário da América Latina e, em especial, do Brasil, estes eram vistos como "atrasados" pelo modelo de desenvolvimento capitalista. Portanto, a modernização desse espaço foi proposta como solução, sob o pretexto de erradicar a fome e fomentar o desenvolvimento. Nesta perspectiva, Gómez (2006, p.185) afirma que

\begin{abstract}
Ao mesmo tempo, essa febre produtivista, que em teoria beneficiaria os países pobres, servia tanto para aumentar a produção de matérias-primas baratas, destinadas às agroindústrias do denominado Primeiro Mundo que as beneficiavam, incrementando seu valor, como para aumentar a produção de maquinário e insumos químicos desses países ricos que vendiam para os países pobres.
\end{abstract}

Pode-se dizer, então, que a Revolução Verde foi a implantação de tecnologias no campo, seja na agricultura ou na pecuária, visando o aumento da produtividade. O desenvolvimento do campo brasileiro, passou a ser concebido por meio do uso de máquinas como trator e colheitadeiras, a inserção de sementes geneticamente modificadas e o uso de agrotóxicos. Entretanto, na verdade, a utilização deste pacote beneficiava os países já desenvolvidos que além de venderem maquinários, lucravam com a transformação dos produtos primários.

Para entender essa relação é interessante verificar como aconteceu o processo de modernização da agricultura brasileira. Para Graziano (1996) a modernização teve quatro fases: a primeira, diz respeito a transformação da base técnica, com o aumento do índice de uso de insumos e maquinários, o que era feito através da importação por meio do apoio do governo brasileiro; a segunda, refere-se a industrialização da produção rural com a inserção de indústrias de bens de produção e de alimentos; a terceira, caracteriza-se pela integração entre agricultura e indústria e, por fim, a quarta, caracteriza-se pela integração de capitais (industriais, bancários e agrários) sob o comando do capital financeiro.

Salienta-se que o Estado brasileiro teve papel importante na constituição da modernização da agricultura. A este respeito, Matos e Pêssoa (2011, p.303) fracionam a participação do Estado em três momentos: 
[...] o primeiro, de 1960 até início dos anos 1980, em que o Estado cumpriu o papel de indutor e financiador da agricultura moderna no país e, que, por isso, é caracterizado como uma fase de expressão máxima de apoio do Estado. [...] O segundo período vai de 1980 a 1990 e é marcada pela diminuição das políticas agrícolas, isto é, pelo desmonte de um projeto estatal. E, o último, período pós 1990, em que ocorre a reestruturação das políticas agrícolas e a adesão às políticas neoliberais.

Assim, num primeiro momento, na década de 60, o Brasil importava essas tecnologias, principalmente, dos Estados Unidos. Posteriormente, com o advento da Ditadura Civil-Militar e, por consequência, uma maior comunicação deste governo com as multinacionais estrangeiras, estas tiveram uma série de benefícios para se instalar no Brasil facilitando e intensificando a integração entre indústria e agricultura, resultando no chamado Complexo Agroindustrial (CAI). Neste sentido, Marafon (1998, p. 2) diz que

A constituição do Complexo Agroindustrial em nosso país envolveu a internalização da indústria de máquinas, equipamentos e insumos e a modernização e expansão do sistema agroindustrial que foi regulamentada através das políticas estatais (políticas de fomento agrícola).

De acordo com Müller (1989, p.41) Complexo Agroindustrial é conceituado como sendo o

[...] conjunto de relações entre indústria e agricultura na fase em que esta mantém intensas conexões para trás, com a indústria para a agricultura e para frente, com as agroindústrias e outras unidades de intermediação que exercem impactos na dinâmica agrária. O Complexo Agroindustrial é uma forma de unificação das relações entre os grandes departamentos econômicos com os ciclos e as esferas de produção, distribuição e consumo, relações estas associadas às atividades agrárias.

Desta forma, com a implantação do Complexo Agroindustrial ocorre o processo de “industrialização da agricultura”, o qual para Teixeira (2005, p. 33), ocorreu a partir do momento em que "[...] a indústria a montante é a fornecedora de bens de capital e insumos para a agricultura e a indústria a jusante é a processadora de matéria prima agrícola, denominada de agroindústria".

Portanto, a agricultura se torna dependente da indústria, visto que ela necessita de máquinas e de insumos para produzir e, após a produção, novamente depende da indústria para o processamento da matéria prima. Com as transformações no campo brasileiro este adquire novas características, sendo que as relações cidade-campo se modificam tornando-se dependentes. De David (1992, p. 47) aponta que 
As novas articulações da agricultura conferem também novas redefinições em torno das relações campo - cidade advindas da vinculação ao setor urbano industrial. $\mathrm{O}$ agricultor relaciona-se, agora, diretamente com o urbano, sede do capital, da indústria, do comércio e dos serviços necessários a produção agrícola.

Nesta perspectiva, o produtor rural que se inseriu no Complexo Agroindustrial, ficou dependente da cidade, pois é neste espaço que ele vai comercializar sua produção, bem como obter insumos e maquinários para produzir.

Conforme aponta a Teixeira (2005) a modernização da agricultura diz respeito a dois aspectos, sendo que um deles se refere a questão da modernização e introdução das tecnologias no campo enquanto o outro diz respeito às mudanças nas relações sociais decorrentes da primeira. Assim, após dissertarmos sobre a gênese e o processo de modernização da agricultura, faz-se necessário que nos voltemos para as consequências sociais que esta trouxe.

Vale lembrar que um dos argumentos para a implementação da modernização da agricultura nos países "subdesenvolvidos" era a finalidade de erradicar a fome do mundo com o aumento da produtividade e, por consequência, haveria a promoção do desenvolvimento. Entretanto, algumas ponderações se fazem necessárias, como: A fome do mundo acabou? Os países latinos se desenvolveram? Sobre estas indagações Hespanhol (2008, p.372-373) afirma que

[...] o modelo produtivista, próprio do modelo no qual se insere a agricultura moderna, não proporcionou a superação da pobreza das zonas rurais, nem proporcionou a melhoria da qualidade de vida das suas populações. A agricultura moderna também não levou a superação do problema da fome no planeta, apesar de ter havido a ampliação da oferta de alimentos, os problemas relacionados à sua distribuição perduraram e até se agravaram.

Destarte, apesar da oferta de alimentos ter aumentado, este modelo produtivista não proporcionou uma melhora na qualidade de vida das populações do campo, nem levou a superação da fome no mundo, pois essa questão não está relacionada apenas a produção de alimentos, mas também a distribuição de renda e, consequentemente, de alimentos entre os indivíduos.

De acordo com Matos e Pêssoa (2011, p.317) salienta-se que

Não adianta ter crescimento na produção e na produtividade se existem milhares de pessoas passando fome ou se alimentando mal por conta dos altos preços dos alimentos, se a biodiversidade dos biomas está virando cinza; se os recursos hídricos estão se esgotando; se milhares de trabalhadores estão morrendo por conta das 
condições de trabalho; além do êxodo rural e de tantos outros problemas advindos desse modelo dito modernizador, desenvolvimentista e produtivista.

Deve-se considerar que além da perversa distribuição dos alimentos, existe também o fato de que os melhores alimentos, em termos nutricionais, são vendidos a um preço alto, dificultando e/ou impedindo o acesso das massas populares a esses produtos. Neste sentido, fica nítido que além da produção ter se tornado mais artificial, a expansão vertiginosa do processo de urbanização e as mudanças de hábitos, em especial, também massificou o consumo de produtos mais artificiais. Para Matos e Pêssoa (2011, p.300) verifica-se que

\begin{abstract}
Essa relação/dependência foi possível graças, sobretudo, a dois fatores: a agricultura passou a utilizar meios mais artificiais (insumos, máquinas, pesticidas), em detrimento dos naturais (adubação animal); e a população aderiu a uma alimentação mais artificial, procedente das agroindústrias, como os enlatados, processados e também a alimentos, até então, alheios aos hábitos alimentares dos brasileiros como os derivados da soja (óleo, margarina), do trigo (farinha), as carnes de frango de granja, entre outros produtos. Os produtos alimentícios artificiais cada vez mais foram ganhando mercado, adeptos e consumidores, garantindo a reprodução do capital agroindustrial.
\end{abstract}

Portanto, é neste contexto que devemos lembrar que além da morte pela fome, nós também temos a morte pela obesidade. A Organização das Nações Unidas para Alimentação e Agricultura (FAO, 2014) estima que mais de 50\% da população brasileira esteja com sobrepeso e $20 \%$ das pessoas adultas estão com obesidade, sendo muito comum a morte destes por subnutrição. Portanto, a qualidade do que é produzido também é muito incipiente, pois o alimento artificial não oferece os nutrientes necessários aos consumidores para que estes tenham uma boa qualidade de vida (ESTEVE, 2017).

Pode-se afirmar, então, que a modernização da agricultura, modo de vida e hábitos alimentares estão diretamente relacionados. A partir do momento em que a agricultura passa a incorporar insumos e agrotóxicos a sua produção, ela deixa de produzir de forma natural e se torna artificial, resultando assim na redução na qualidade dos alimentos e trazendo profundas alterações à população.

Além disso, a introdução de maquinários libera mão de obra para as cidades, o chamado êxodo rural, onde o ritmo de vida é muito mais acelerado e então incorpora-se o consumo de alimentos prontos, o que até então era impensável. Somado a isto, com a rápida transferência da população rural do campo para as cidades, o discurso da necessidade de aumentar a produtividade é fortalecido bem como o de incorporar novas áreas de cultivo, através da chamada "fronteira agrícola". 
Teixeira (2005, p. 36) coloca que apesar de “[...] não excluir totalmente as pequenas propriedades, a modernização agrícola se concentrou basicamente nas grandes propriedades, tornando-se seletiva". Vale lembrar que o Estado brasileiro teve um papel importante neste processo, pois foi através de programas governamentais que tornaram a modernização possível. De acordo com Andrade (1979, p.10) ressalta-se a que

Os órgãos governamentais estimularam a modernização da agricultura, dando aos proprietários médios e grandes uma série de vantagens e de facilidades, deixando marginalizados os pequenos proprietários e os trabalhadores sem-terra. Assim, em nome de um aumento da produtividade e de uma diminuição do custo da produção, estimulou-se a mecanização agrícola, provocando [...] desemprego dos trabalhadores.

Nesta perspectiva, fica nítido o caráter seletivo e concentrador da modernização da agricultura, visto que nem todos os produtores tiveram condições de acesso e um contingente expressivo teve suas terras expropriadas, precisando migrar para as cidades ou vender sua mão de obra para um grande produtor. Sob este ponto de vista, Andrade (1979, p.60) explana que “[...] essa expansão do modo de produção capitalista se caracteriza pelo fato do trabalhador rural se proletarizar, isto é, tornar-se um assalariado que vende a sua força de trabalho e recebe uma remuneração em dinheiro".

Salienta-se que as políticas de comercialização também privilegiaram os setores produtivos voltados para atender ao mercado externo e não na agricultura familiar, a qual produz alimentos importantes para atender a demanda local/regional e também mais saudáveis para a população. De acordo com Elesbão (2007) historicamente as políticas agrícolas privilegiaram a agricultura de exportação, resultando na monocultura. Matos e Pêssoa (2011, P. 312) afirmam que

O Brasil é um dos líderes mundiais em produção e exportação de vários produtos agropecuários. É o primeiro em produção e exportação de café, açúcar, álcool e sucos de frutas. Além disso, lidera as vendas de soja, milho, carne bovina, carne de frango, tabaco, couro e calçados de couro. No que se refere à soja, o Brasil ostenta o segundo lugar na produção, perdendo apenas para os Estados Unidos.

Portanto, verifica-se que a modernização da agricultura é contraditória, pois à medida que ela vai se intensificando e agregando novas áreas, possibilitando o aumento do acúmulo de capital, a concentração (de terras e de riquezas) também vão crescendo.

Quanto aos programas de desenvolvimento para o campo, Andrade (1979, p.47) salienta que 
Os programas de desenvolvimento agrário só podem ser classificados como tais, se vêm contribuir para a melhoria das condições de vida no campo, para a fixação do homem ao meio, permitindo que absorva os benefícios da civilização sem que seja expulso, degradado, empobrecido.

Deste modo, fica visível que este modelo de desenvolvimento agrário é contraditório e está ultrapassado. Enquanto poucas empresas/latifundiários detém a maioria das terras brasileiras, sendo que muitas delas são estrangeiras, diversos agricultores são privados do seu acesso à terra, e esta deixou de cumprir com sua função social, passando a ser uma mera mercadoria.

\section{DINÂMICAS PRODUTIVAS NO MUNICÍPIO DE TOROPI-RS}

Sob a perspectiva da modernização da agricultura, o munícipio de Toropi também foi alvo destes processos que reestruturaram o campo brasileiro. Deste modo, através da coleta de dados primários e da produção de informações, foi possível verificar as principais dinâmicas produtivas na unidade territorial em análise, seja em relação a introdução de agroindústrias, com a criação de cooperativas ou com as mudanças na agricultura e/ou na pecuária.

Neste sentido, a criação de cooperativas foi um dos fatores que contribuiu para a efetivação da modernização da agricultura, visto que, através destas, os agricultores tiveram acesso ao pacote tecnológico, como implementos agrícolas, agrotóxicos, sementes modificadas, assistência técnica, entre outros (DE DAVID, 1992). Destaca-se que no município de Toropi, os agricultores locais viram a necessidade de investir em uma nova cooperativa, visto que a localidade carecia de locais para armazenar a produção, além de haver dificuldades para o escoamento da safra, ausência de crédito e insumos (TRABALHO DE CAMPO ${ }^{3}, 2018$ ).

No dia 29 de abril de 1964, um grupo de sessenta e dois agricultores, fundaram a Cooperativa Mista dos Agricultores de Toropi (COOMAT) a qual podemos visualizar na Figura 2. Estes agricultores eram liderados por um Pastor Evangélico Luterano, Ari Pfluck, vindo da região de Lajeado, o qual já possuía experiência com o cooperativismo, pois nesta região já funcionavam cooperativas agrícolas e de crédito (COOMAT, 2015).

\footnotetext{
${ }^{3}$ Informações obtidas em trabalho de campo através de entrevista com representante da Cooperativa Mista dos Agricultores de Toropi (COOMAT).
} 


\section{Figura 2: Vista aérea da matriz da COOMAT, em Toropi-RS}

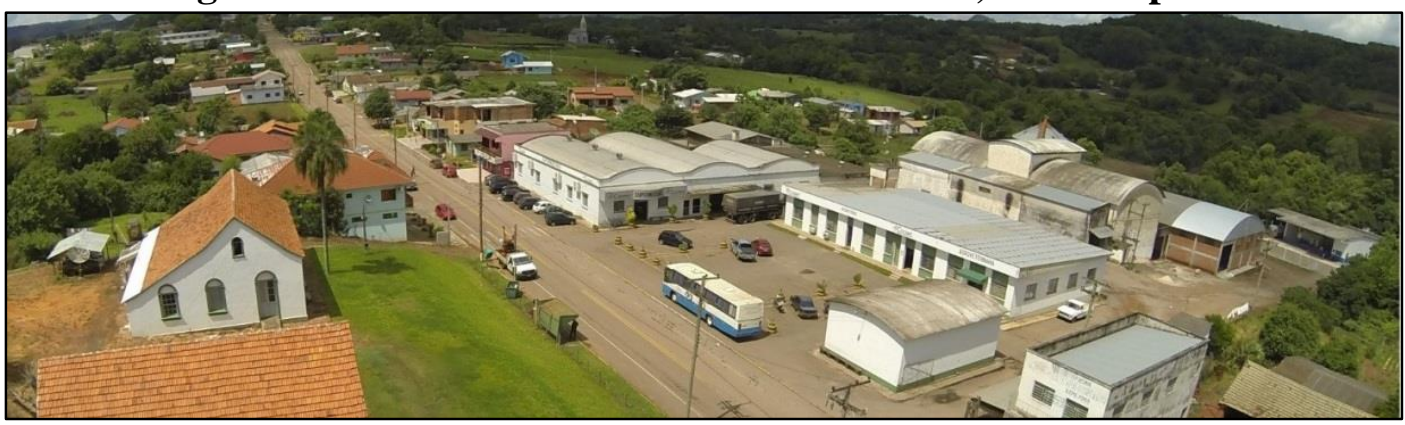

Fonte: Cooperativa Mista dos Agricultores de Toropi (COOMAT), 2015.

A partir da comercialização de grãos, a matriz, em Toropi, aumentou sua estrutura de armazéns, atingindo hoje a capacidade de armazenagem de 65.000 mil sacos de produtos a granel e 20.000 de produtos ensacados. Além disso, possui um posto de recebimento e resfriamento de leite, com capacidade de 35.000 mil litros/dia. Juntamente, dispõe de laboratório próprio de análise, para o controle de qualidade do leite (COOMAT, 2015).

É importante destacar que a instalação das agroindústrias foi outra característica resultante da expansão da lógica produtiva urbano-industrial, a qual foi possível em razão do papel preponderante do Estado brasileiro na viabilização deste processo, principalmente, através da oferta de crédito rural. Neste sentido, é ainda durante o governo do Estado de Pedro Simon (1987-1990) que diversos técnicos da Secretaria de Estado da Agricultura e Abastecimento (SAA), buscaram sanar problemas relacionados as pequenas propriedades agrícolas do Rio Grande do Sul. Para isso, realizaram-se estudos a partir de exemplos de agroindústrias já implantadas nos municípios de Santa Catarina. Após estes levantamentos e informações, o governo do estado buscou oferecer crédito aos produtores rurais através do Fundo Estadual de Apoio ao Desenvolvimento dos Pequenos Estabelecimentos Rurais FEAPER (GULLO, 2001).

Desta forma, o crédito rural foi oferecido em etapas. Em um primeiro momento era voltado para a eletrificação rural e a construção de galpões para o armazenamento da produção, o qual ocorria via recursos do Banco Nacional de Desenvolvimento Econômico e Social (BNDES). Posteriormente, os recursos passaram a serem disponibilizados para viabilizar a introdução de investimentos nas pequenas propriedades (GULLO, 2001).

O fundo FEAPER foi de fundamental importância para as pequenas propriedades, fomentando o Programa de Condomínios Rurais, o qual foi o mais importante da década de 90. Em relação a estes, Gullo (2001, p.48) diz que os Condomínios Rurais são “[...] uma forma de 
organização associativa, de pequenos proprietários rurais vizinhos, que se unem para viabilizar soluções econômicas, sociais, políticas e culturais". Por meio dessa organização os “pequenos agricultores" se organizam para se inserirem no mercado.

Paralelamente, destaca-se o papel fundamental da EMATER para a efetivação dos Condomínios Rurais, uma vez que os técnicos eram responsáveis por prestar assistência aos proprietários. Enfatiza-se também que estas associações tinham por característica possuírem um número menor de associados, se comparado às cooperativas. Elas foram criadas baseadas no modelo uruguaio, onde a média estava entre 10 a 12 proprietários (OLIVO, 2000).

De acordo com Olivo (2000, p.58) “A ideia também estava fundamentada na necessidade de desenvolver determinadas atividades que até então haviam sido pouco desenvolvidas com a cooperação agrícola, como a exploração leiteira e de suínos”. Neste sentido, o Condomínio de Toropi, ao ser constituído, voltou sua produção para a criação de suínos.

Portanto, no ano de 1992 foi inaugurado o condomínio rural de Toropi, o qual possuía um total de 22 associados. No entanto, em 1998 a associação se desagregou e as instalações deste condomínio foram vendidas a um único proprietário, o qual o possui até o presente sob o nome de Granja Toropi (Figura 3) (TRABALHO DE CAMPO ${ }^{4}, 2018$ ).

\section{Figura 3: Instalações da Granja Toropi-RS}

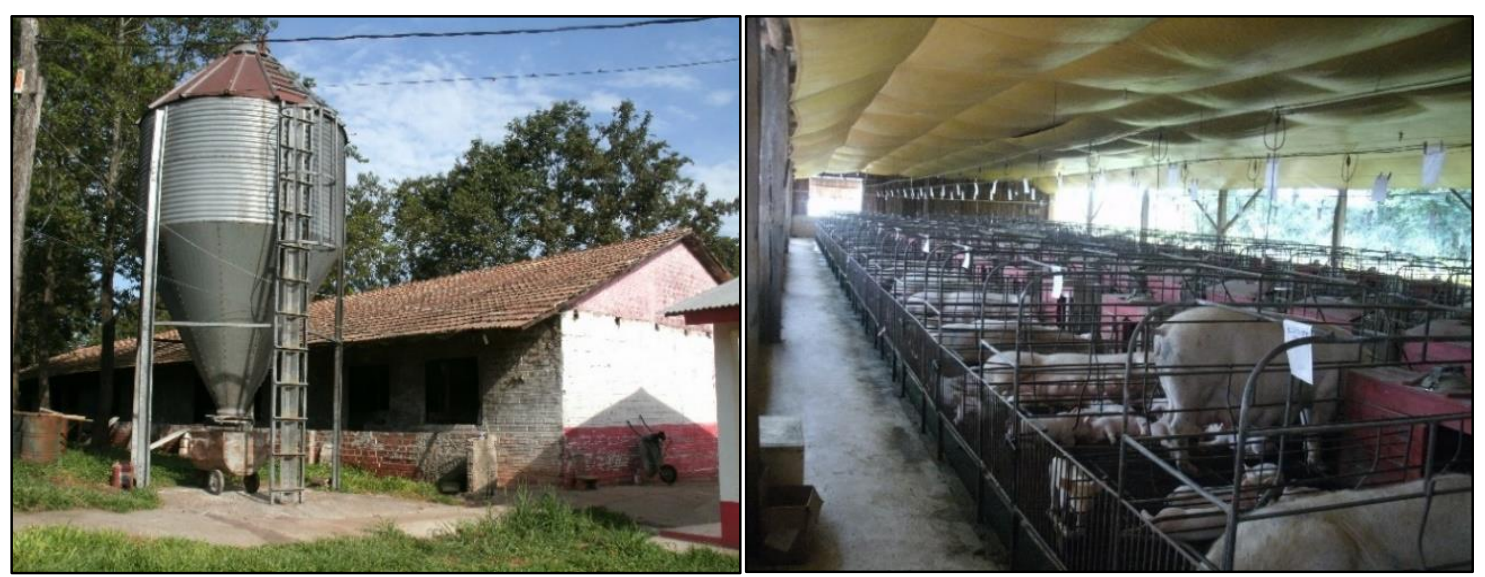

Fonte: Trabalho de Campo, 2018. Organizado pelas autoras.

Atualmente a Granja Toropi está assentada no trabalho assalariado, onde 16 pessoas são empregadas para desenvolverem atividades como os trabalhos de limpeza, de controle da

${ }^{4}$ Informações obtidas em trabalho de campo com o representante da Granja Toropi. 
criação dos porcos à trabalhos administrativos, sendo que no ano da entrevista (2018), todos os empregados eram oriundos do próprio município de Toropi (TRABALHO DE CAMPO², 2018).

Em relação à alimentação para a pecuária, as rações são comercializadas com a COOMAT, incentivando, portanto, a economia e o desenvolvimento local. No entanto, toda a produção da Granja é vendida para a BRF Brasil de Lajeado-RS, representando, deste modo, a perca da autonomia na produção e, também, a submissão do processo produtivo aos padrões impostos pelas grandes empresas, visto que durante a produção diversos fatores são observados, como peso e alimentação, período de abate, entre outros. (TRABALHO DE CAMPO², 2018).

Além da Cooperativa e da Granja Toropi, durante o trabalho de campo, foi possível perceber outras formas de "urbanização" do rural. Uma delas foi a presença de uma agroindústria na localidade de Passo de Galvão. A Padaria, denominada Agroindústria Santa Bárbara, comercializa com os moradores locais e fornece merenda para a escola municipal por meio do Programa Nacional de Alimentação Escolar (PNAE) ${ }^{5}$.

Paralelamente a implantação destas agroindústrias, outras transformações, seja na agricultura ou na pecuária, foram verificadas. O gráfico 1 permite observar que $65,8 \%$ dos entrevistados deixaram de exercer alguma atividade no meio rural como o plantio de fumo, soja, leite entre outros.

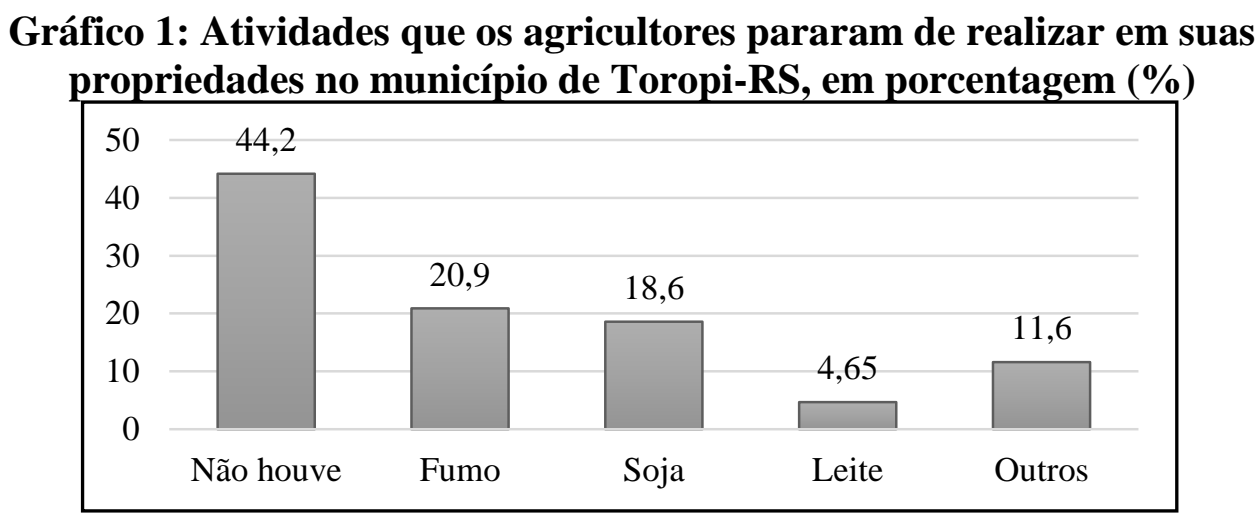

Fonte: Trabalho de campo, 2018. Organizado pelas autoras.

Neste sentido, 18,6\% dos agricultores deixaram de plantar soja entre os anos de 1980 e 2000, os quais alegaram que esta é uma cultura pouco rentável para a pequena propriedade familiar visto que estes trabalhadores não possuíam condições financeiras de adquirir esse "pacote

\footnotetext{
${ }^{5}$ Vale lembrar que o PNAE é um programa do governo federal que envia recursos para os Estados e os Municípios, visando garantir que os produtos oriundos da agricultura familiar sejam comercializados (www.fnde.gov.br/programas/pnae, 2018).
} 
tecnológico" oriundo da modernização da agricultura. Além disso, essa cultura demandava de uma elevada mão de obra, visto que não tinham a possibilidade de comprar maquinários para a colheita, a qual era realizada manualmente, com a soja cortada de foice e, logo após, trilhada.

Portanto, este cultivo era muito trabalhoso e pouco rentável, fazendo com que muitos agricultores migrassem para outras culturas mais rentáveis nas pequenas propriedades, como é o caso do fumo. Então, entre o início dos anos 1990 e 2000 muitos agricultores familiares passaram a ter, no cultivo do fumo, a sua principal fonte de renda.

Apesar da relevante rentabilidade, o cultivo do fumo também apresenta algumas dificuldades levando 20,9\% dos entrevistados a desistirem desta atividade. Dentre os fatores citados para este abandono podemos destacar a relação com doenças decorrentes do uso intenso de agrotóxicos, problemas oriundos do grande esforço físico, falta de mão de obra familiar e aposentadoria.

Além do fumo e da soja, a produção leiteira passou por mudanças significativas nos últimos anos. No município de Toropi, 4,65\% dos entrevistados abandonou esta produção, devido à sua baixa lucratividade para o agricultor familiar. As elevadas exigências impostas pela vigilância sanitária, elaboradas conjuntamente com empresas de lacticínios, acabam por beneficiar apenas os grandes produtores

Nesse sistema, os agricultores familiares ficam marginalizados sem as devidas condições de "competir" com quem produz em grande escala. Assim, além de não conseguirem se adequar as exigências sanitárias, pois a produção leiteira para o pequeno produtor vem mais no sentido de complementar a renda do que de ser a atividade principal da propriedade, o preço ofertado pelo litro de leite é irrisório, sendo que nos primeiros meses de 2018 o litro chegou a ficar abaixo dos $\mathrm{R} \$$ 0,60. Portanto, o produtor rural acaba por cessar está atividade com fins comerciais na propriedade.

Os demais 11,6\% pararam de exercer atividades variadas, sendo elas: produção de uva, queijo e arroz. A produção de uvas, deixou de ser realizada na propriedade entrevistada devido à redução da produtividade a qual está relacionada ao uso de agrotóxicos, principalmente em lavouras de soja que passaram a ser cultivadas nas proximidades. Quanto ao arroz, a maior parte de sua área foi substituída pela soja. No que se refere a produção de queijo, assim como o leite, as elevadas exigências para a produção foram um empecilho, somado a ilegalidade da comercialização de queijos feitos a partir do leite cru no estado gaúcho. 
Apesar dos agricultores terem abandonado algumas atividades, conforme o gráfico 2, a atividade agrícola predominante no município de Toropi-RS continua sendo a fumicultura associada à produção de milho. Observa-se que 55,8\% dos agricultores entrevistados produzem fumo e milho, sendo que o primeiro é o que mais gera renda nas pequenas unidades produtivas locais.

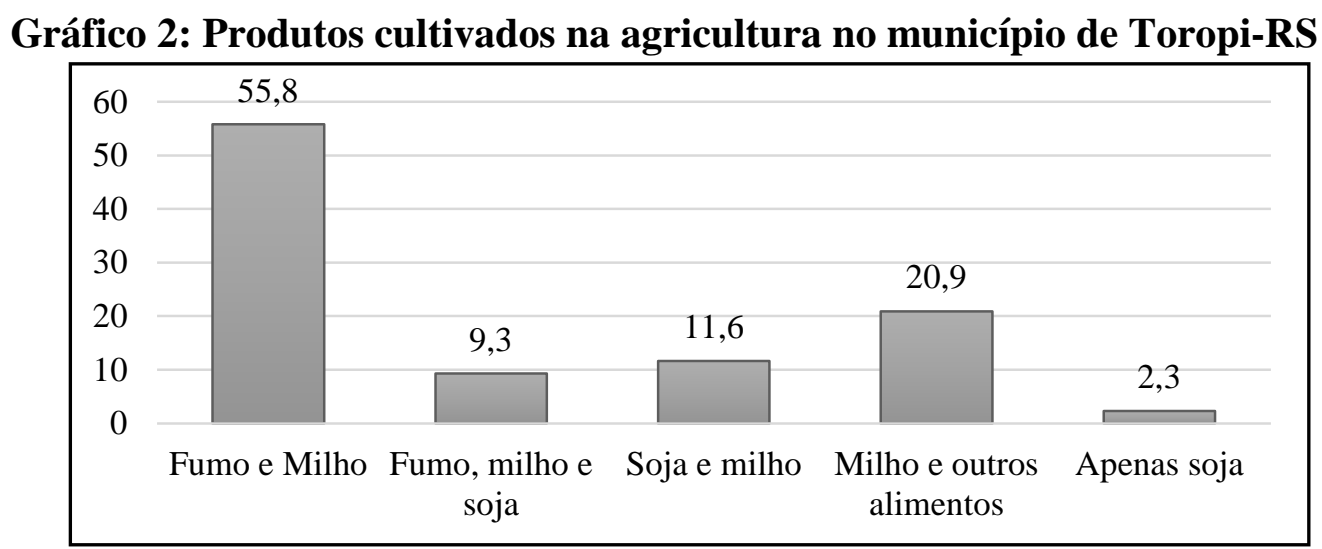

Fonte: Trabalho de Campo, 2018. Organizado pelas autoras.

Salienta-se que o plantio do fumo é consorciado com a produção de milho, visto que o primeiro é plantado após o inverno e colhido no início do verão. Deste modo, o milho é plantado nas restevas ${ }^{6}$ do fumo, entre os meses de dezembro e janeiro. Este sistema de produção consorciada é muito benéfico para o agricultor, visto que além dele comercializar o fumo ele ainda produz o milho na mesma área, aproveitando inclusive insumos que foram usados para a produção do fumo, como ureia e adubos, que acabam ficando no solo. Além disso, o milho é produzido para o autoconsumo e quando há excedentes é comercializado na COOMAT.

Em menor expressividade, 9,3\% são os produtores que além de cultivarem fumo e milho, ainda produzem soja em sua propriedade. Vale lembrar que os agricultores familiares com menores condições econômicas não possuem maquinários para plantar, pulverizar e/ou colher a soja. Neste sentido, a troca de serviços é uma prática comum entre os agricultores, sendo que, aqueles que possuem máquinas fazem todos os serviços necessários na cultura da soja e, posteriormente, estes agricultores prestam serviços braçais/manuais a quem o emprestou o maquinário (GRÁFICO 2).

Além disso, outros 11,6\% dos agricultores se aventuraram na produção da soja. Assim como os anteriores, muitos destes também trocam serviços com agricultores que possuem mais

\footnotetext{
${ }^{6}$ Resteva é uma denominação local para as lavouras onde foram plantadas o fumo. Esta denominação é utilizada pois após a colheita de fumo ficam restos (tocos) do tronco do tabaco bem como insumos aplicados na lavoura.
} 
capital. Outros 2,3\% dos entrevistados produzem apenas soja. Estes já possuem médias propriedades e um número maior de equipamentos, além de arrendarem outras propriedades para o plantio da soja. Por fim, os demais $20,9 \%$ dos entrevistados declararam plantar apenas para o autoconsumo, destacando-se o milho, feijão, mandioca entre outras culturas (GRÁFICO 2).

Como podemos perceber, a agricultura é fundamental para a manutenção da vida no espaço rural. No entanto, além dela, a pecuária também apresenta relevância no município em questão, seja na produção de alimentos para as famílias ou até mesmo na comercialização com vizinhos e/ou atravessadores. Deste modo, é um agregador de valor para estas famílias, contribuindo para a geração de renda e, por consequência, para a permanência delas no campo.

Conforme os dados obtidos no trabalho de campo, 95,3\% dos entrevistados declaram que a pecuária é consorciada com a agricultura. Salienta-se que os demais $4,7 \%$ que não praticam a agricultura consorciada com a pecuária, dedicam-se a atividades comerciais como a presença de um minimercado em uma das propriedades e o outro caso configura-se como turismo rural na localidade do Balneário Passo do Angico.

\section{CONSIDERAÇÕES FINAIS}

A organização do espaço e suas respectivas relações socioculturais são constantemente transformadas pelos interesses do capital. Neste sentido, um dos processos que acarretou profundas mudanças para o espaço rural e seus habitantes foi a modernização da agricultura. Esta possui um caráter seletivo, sendo que a maior parte dos agricultores são marginalizados deste processo e, neste sentido, várias foram as políticas públicas criadas pelo Estado brasileiro, o que possibilita perceber sua participação ativa para a implantação deste projeto no Brasil, as quais buscaram inserir os agricultores familiares nesta lógica da produção.

Nesta perspectiva, as cooperativas foram importantes, uma vez que possibilitaram a comercialização de produtos oriundos do pacote tecnológicos nos locais mais longínquos. Em Toropi, tal acontecimento pode ser verificado através criação da COOMAT, a qual passou a facilitar a entrada de insumos, agrotóxicos e assistência técnica, voltando-se para a lógica produtivista de produção e, por consequência, facilitando o acúmulo de capital para grandes empresas do ramo agropecuário.

No entanto, ainda em relação a modernização da agricultura, devemos lembrar que, apesar das políticas públicas e dos subsídios proporcionados pelo Estado, uma parcela 
significativa dos agricultores familiares não conseguiram se "modernizar". Neste sentido, a exclusão de agricultores familiares do campo é muito frequente, ocasionado ou a proletarização do agricultor ou o êxodo rural no município.

Além disso, a "industrialização do campo" foi outra consequência da modernização da agricultura local. Neste sentido, o município de Toropi-RS conta com a presença de uma agroindústria - padaria-, um minimercado localizado no interior do município e a Granja Toropi, a qual possui como especialização a produção de suínos.

Neste sentido, percebe-se que essas atividades são de suma importância para a manutenção destes agricultores familiares no campo, uma vez que elas representam a viabilidade de sua manutenção no espaço rural. Ressaltamos que a presença de atividades historicamente predominantes no município permanece, sendo que a produção fumageira consorciada com o milho é hegemônica. No entanto, apesar das variações verificadas nos dados, percebe-se que houve uma estabilização na produção da cultura fumo nos últimos anos.

Somado a isto, nas áreas de várzeas, próximas ao Rio Toropi, a produção de arroz foi substituída pela soja, a qual vem crescendo no município. Vale ressaltar que a soja vem adentrando no município, sendo produzida especialmente por agricultores que já possuem acesso a mecanização e, outros, onde a prática desta cultura não é tão rentável, há arrendamento da terra para a produção desta cultura. Além da agricultura, 95,3\% das propriedades possuem produção pecuário. Neste ramo, os bovinos predominam em relação aos suínos e galináceos os quais são destinados majoritariamente para o autoconsumo ou para a comercialização com vizinhos.

Deste modo, fica evidente que, apesar de algumas atividades tradicionais no município permanecerem, na atualidade, as formas de produzi-las e as relações de produção se modificaram. Além disso, novas atividades adquiriram significações e, outras, como a agroindústria, passaram a serem desenvolvidas resultando na reorganização espacial no município de Toropi-RS.

\section{REFERÊNCIAS:}

ANDRADE, Manuel Correia de. Agricultura e Capitalismo. São Paulo: Livraria Editora Ciências Humanas, 1979.

Caminhos e descaminhos da geografia. 5 ed. Campinas: Papirus, 2002. 
BRAGA, Paulo Romeu. Os interesses econômicos dos Estados Unidos e a segurança interna do Brasil entre 1946 e 1964: uma análise sobre os limites entre diplomacia coercitiva e operações encobertas. Revista Brasileira de Política Internacional, v. 45, ano 2, p.46-65. 2002.

BRASIL. Lei $\mathrm{n}^{\mathrm{o}}$ 11.326, de 24 de julho de 2006. Estabelece as diretrizes para a formulação da Política Nacional da Agricultura Familiar e Empreendimentos Familiares Rurais. Diário Oficial da União, Brasília, DF, 15 fev. 2018. Disponível: < www.planalto.gov.br/ccivil_03/ato2004-2006/2006/lei/111326.htm>. Acesso em: 15 fev. 2018.

COOPERATIVA MISTA DOS AGRICULTORES DE TOROPI (COOMAT). Coomat: Uma história com 50 anos de trabalho e dedicação. Revista 50 anos COOMAT, 2015. Gráfica Universitária, Santa Maria, 2015.

CORRÊA, Roberto Lobato. Organização espacial. In: Região e organização espacial. 7 ed. São Paulo: Ática, 2003. Cap. 4, p. 51-84. (Série princípios).

DE DAVID, Cesar. O processo de modernização da agricultura e a constituição do complexo agroindustrial no município de Cruz Alta - RS. 1992. 125 p. Monografia (Especialização em Usos e recursos do Espaço do Rio Grande do Sul) - Universidade Federal de Santa Maria, Santa Maria,1992.

ELESBÃO, Ivo. O espaço rural em transformação. Revista Finisterra, XLII, nº 84, p. 47-65, 2007.

ESTEVE, Esther Vivas. O negócio da comida: quem controla nossa alimentação? São Paulo: Expressão popular, 2017.

GÓMEZ, Jorge R. Montenegro. Desenvolvimento em (Des)Construção: Narrativas escalares sobre desenvolvimento territorial rural. 2006. 438p. Tese (Doutorado em geografia) Faculdade de Ciências e Tecnologia, Universidade Estadual Paulista, Presidente Prudente, 2006.

GRAZIANO DA SILVA, José. A nova dinâmica da agricultura brasileira. Campinas: Unicamp, 1996.

GULLO, Maria Carolina Rosa. Fundo Estadual de Apoio ao desenvolvimento dos pequenos estabelecimentos rurais-FEAPER: uma análise dos 10 nos, com ênfase no problema da inadimplência. 2001. 161p. Dissertação (Mestrado em Economia Rural) - Universidade Federal do Rio Grande do Sul, Porto Alegre, 2001.

HARVEY, David. A produção capitalista do espaço. 2 ed. São Paulo: Annablume, 2006.

INSTITUTO BRASILEIRO DE GEOGRAFIA E ESTATÍSTICA. Cidades. 2018. Disponível em: <cidades.ibge.gov.br/brasil/rs/toropi/historico>. Acesso em: 29 jul. 2018.

HESPANHOL, Antonio Nivaldo. Modernização da agricultura e desenvolvimento territorial. $4^{\mathbf{0}}$ Encontro Nacional de Grupos de Pesquisa - ENGRUP, São Paulo, p. 370-392. 2008. 
INSTITUTO BRASILEIRO DE GEOGRAFIA E ESTATÍSTICA. Censo agropecuário 2006. Rio de Janeiro, $2006 . \quad$ Disponível em:< biblioteca.ibge.gov.br/visualizacao/periodicos/50/agro_2006_agricultura_familiar.pdf>. Acesso em: 23 fev. 2018.

MARAFON, Glaúcio José. Industrialização da agricultura e formação do Complexo Agroindustrial no Brasil. Revista Educação Pública, Rio de Janeiro. 1998. Disponível em: <www.educacaopublica.rj.gov.br/biblioteca/geografia/0006.html>. Acesso em: 01 jun. 2018.

Principais transformações em curso no espaço rural na atualidade. Revista Geográfica de América Central, Costa Rica, no especial, I semestre, p. 69-84, 2011.

MATOS, Patrícia Franscisca; PÊSSOA, Vera Lúcia Salazar. A modernização da agricultura no Brasil e os novos usos do território. Geo UERJ, Rio de Janeiro, ano 13, nº 22, v.2, p. 290-322, 2011.

MOREIRA, Ruy. A formação espacial brasileira: contribuição crítica aos fundamentos espaciais da geografia do Brasil. 2 ed. Rio de Janeiro: Consequência, 2014.

MÜLLER, Geraldo. Complexo Agroindustrial e modernização agrária. São Paulo: Hucitec, 1989.

OLIVO, Clair Jorge. Sustentabilidade de condomínios rurais formados por pequenos agricultores familiares: Análise e proposta de modelo de gestão. 2000, 269p. Tese (Doutorado em Engenharia de Produção) - Universidade Federal de Santa Catarina, Florianópolis, 2000.

ORGANIZAÇÃO DAS NAÇÕES UNIDAS PARA ALIMENTAÇÃO E AGRICULTURA. Sobrepeso e obesidade aumentam no Brasil conforme relatório da FAO e OPAS. Roma Itália, 2018. Disponível em: <www.fao.org/americas/noticias/ver/pt/c/466066/>. Acesso em: 01 jun. 2018.

RUA, João. Urbanidades no rural: o devir de novas territorialidades. Campo-Território: Revista de Geografia Agrária, Uberlândia, v. 1, n. 1, p. 82-106, 2006.

SANTOS, Milton. Espaço e Método. 3 ed. São Paulo: Nobel, 1992. (Coleção Espaços).

Metamorfose do espaço habitado. São Paulo: HUCITEC, 1988.

TEIXEIRA, Jodenir Calixto. Modernização da agricultura no Brasil: impactos econômicos, sociais e ambientais. Revista Eletrônica da Associação dos Geógrafos Brasileiros, Três Lagoas-MS, ano 2, no 2, v. 2, p.21-42, 2005.

Recebido em Julho de 2019

Aceito em Outubro de 2019

Publicado em Dezembro de 2019 